\title{
Living Cationic Polymerization of 2-Chloroethyl Vinyl Ether with Iodine and Hydrogen Iodide/Iodine Initiators
}

\author{
Toshinobu Higashimura, Yan-Ming LAw,* and Mitsuo Sawamoto \\ Department of Polymer Chemistry, Faculty of Engineering, \\ Kyoto University, Kyoto 606, Japan
}

(Received February 8, 1984)

\begin{abstract}
This paper is concerned with the living cationic polymerization of 2-chloroethyl vinyl ether (CEVE). Living poly(CEVE) of a nearly monodisperse molecular weight distribution (MWD) $\left(M_{w} / M_{n} \lesssim 1.1\right)$ was obtained in toluene at $-40^{\circ} \mathrm{C}$ with a mixture of hydrogen iodide (HI) and iodine as initiating system. The number-average molecular weight $\left(M_{n}\right)$ of the polymer increased proportionally to CEVE conversion, while the MWD remained nearly monodisperse throughout the reaction. An excess amount of $\mathrm{HI}$ over iodine was needed to achieve this living process. The polymerization at $-15^{\circ} \mathrm{C}$ by the $\mathrm{HI} / \mathrm{I}_{2}$ initiator in toluene or $\mathrm{CCl}_{4}$ also led to living polymers with $M_{n}$ directly proportional to conversion, but their MWD was slightly broader $\left(M_{w} / M_{n}=1.2-1.3\right)$. Iodine alone as initiator resulted in long-lived (but not perfectly living) polymers at $-15^{\circ} \mathrm{C}$ in toluene. Although the $M_{n}$ of the polymers increased proportionally to conversion, their MWD was much broader $\left(M_{w} / M_{n}=1.4-1.6\right)$ than with the $\mathrm{HI} / \mathrm{I}_{2}$ initiator, indicating a slower initiation by this initiator.

KEY WORDS 2-Chloroethyl Vinyl Ether / Iodine / Hydrogen Iodide /

Cationic Polymerization / Living Polymerization / Molecular Weight

Distribution / Monodisperse Polymer /
\end{abstract}

Cationic polymerization of vinyl compounds usually involves a propagating species that is too unstable to possess a long lifetime or "living" character. In spite of this, we have recently succeeded in living cationic polymerizations $^{1}$ of $p$-methoxystyrene, ${ }^{2,3} \quad N$-vinylcarbazole, ${ }^{4,5}$ vinyl ethers, ${ }^{6-8}$ and related monomers with iodine or hydrogen iodide (HI)/iodine initiator. For example, isobutyl vinyl ether (IBVE), polymerized with hydrogen iodide/iodine initiator in hexane at $-15^{\circ} \mathrm{C}$, gave living polymers with a nearly monodisperse molecular weight distribution (MWD) and controlled molecular weight. ${ }^{7}$ Apparently, the monomers for living cationic polymerization should have an electrondonating substituent that stabilizes the propagating carbocation. ${ }^{1}$
This investigation aims at extending the scope of our living cationic systems to the polymerization of 2-chloroethyl vinyl ether (CEVE). From the above viewpoint, CEVE appears to be less suitable for living polymerization, because its alkoxyl substituent, having a weakly electron-withdrawing chlorine atom, will be less effective to stabilize the propagating end than those in alkyl vinyl ethers (e.g., IBVE). In poly(CEVE), however, the chloroethyl group will in turn serve as a functional pendant that offers interesting synthetic possibilities such as chemical modification $^{9}$ and crosslinking thereby. As initiators iodine and its mixture with hydrogen iodide were used. Both yielded living or long-lived poly(CEVE), as described below.

* Visiting Scholar. Present Address: Research Institute of Materials Science, South China Institute of Technology, Guangzhou, China. 


\section{EXPERIMENTAL}

\section{Materials}

CEVE was commercially supplied (Aldrich) and distilled twice over calcium hydride before use (gas chromatographic purity $>99.8 \%$ ). Iodine (Wako Chemicals, purity $>99.9 \%$ ) was used without further purification. Hydrogen iodide was prepared as described elsewhere. ${ }^{7}$ Polymerization solvents (toluene, $\mathrm{CCl}_{4}$, and $\mathrm{CH}_{2} \mathrm{Cl}_{2}$ ) were purified by the usual methods and distilled at least twice over calcium hydride before use. Chlorobenzene as internal standard for gas chromatography was purified by distillation over calcium hydride.

\section{Procedures}

All polymerizations were carried out in a dry nitrogen atmosphere in test tubes equipped with a three-way stopcock. For this procedure ca. $0.2-0.3 \mathrm{mM}$ of adventitious water was usually found in the reaction mixture. The polymerization was initiated by injecting an iodine solution, or successively iodine and hydrogen iodide solutions, to a monomer solution $(0.50 \mathrm{M})$. After a certain interval, ammoniacal methanol was added to terminate the reaction. The conversion of CEVE was determined by gas chromatography with chlorobenzene as internal standard.

The resulting polymer solutions were washed successively with $10 \%$ aqueous sodium thiosulfate solution, $1 \%$ aqueous sodium hydroxide solution, and distilled water, evaporated to dryness on a rotary evaporator at $c a$. $40^{\circ} \mathrm{C}$, followed by a vacuum drying at room temperature to give product polymers. The polymer yield (by gravimetry) was in close agreement with that based on the CEVE conversion by gas chromatography. The MWD of the polymers was measured by gel permeation chromatography (GPC) in chloroform on a Jasco TRIROTAR-II chromatograph fitted with three polystyrene gel columns (Shodex A 802, A 803, and A 804). The number-average and weight-average molecular weights $\left(M_{n}\right.$ and
$M_{w}$ ) of polymers were calculated from GPC curves on the basis of a polystyrene calibration.

\section{RESULTS AND DISCUSSION}

\section{Polymerization with Iodine}

Formation of Long-Lived Polymers. CEVE $(0.50 \mathrm{M})$ was polymerized with iodine $(10 \mathrm{mM})$ as an initiator at $-15^{\circ} \mathrm{C}$ in toluene, $\mathrm{CCl}_{4}$, and $\mathrm{CH}_{2} \mathrm{Cl}_{2}$. As shown in Figure 1, the polymerization rate increased with increasing solvent polarity. An induction phase was observed in $\mathrm{CCl}_{4}$, but not in toluene or $\mathrm{CH}_{2} \mathrm{Cl}_{2}$.

Figure 2 shows the MWD of polymers obtained with iodine in the three solvents. The MWDs were rather broad $\left(M_{w} / M_{n}=1.4-2.0\right)$ with a tailing in the lower molecular weight side. Toluene gave narrower MWDs than $\mathrm{CCl}_{4}$, suggesting a faster initiation in this solvent ( $c f$. Figure 1). The MWD curves for toluene and $\mathrm{CCl}_{4}$ clearly shifted toward higher molecular weight with increasing conversion, but such a shift was very small for $\mathrm{CH}_{2} \mathrm{Cl}_{2}$.

As shown in Figure 3, the $M_{n}$ of poly(CEVE) obtained in toluene and $\mathrm{CCl}_{4}$ was directly proportional to monomer conversion. The $M_{n}$ for $\mathrm{CH}_{2} \mathrm{Cl}_{2}$ solvent also increased with, but not proportionally to, CEVE conversion. These results show that long-lived propagating species form from CEVE with io-

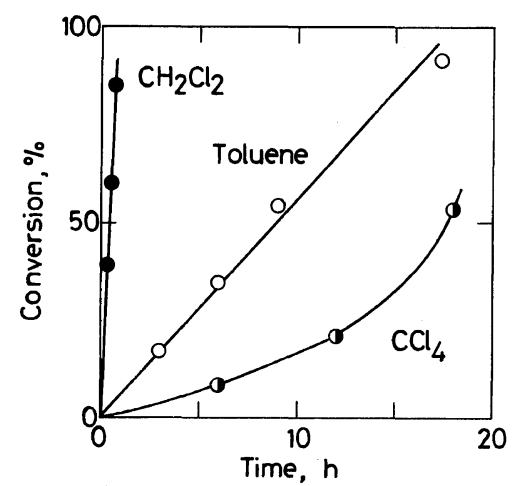

Figure 1. Conversion-time plots for the polymerization of CEVE with iodine at $-15^{\circ} \mathrm{C}:[\mathrm{M}]_{0}=0.50 \mathrm{M}$; $\left[\mathrm{I}_{2}\right]_{0}=10 \mathrm{mM}$. Solvents as indicated. 


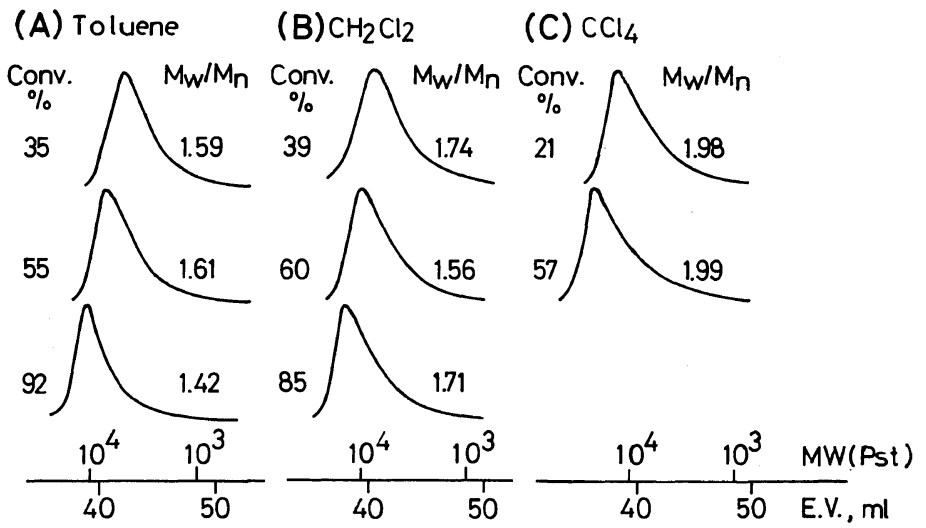

Figure 2. MWD of poly(CEVE) obtained with iodine at $-15^{\circ} \mathrm{C}:[\mathrm{M}]_{0}=0.50 \mathrm{M} ;\left[\mathrm{I}_{2}\right]_{0}=10 \mathrm{mM}$. Solvents, conversions, and $M_{w} / M_{n}$ ratios as indicated.

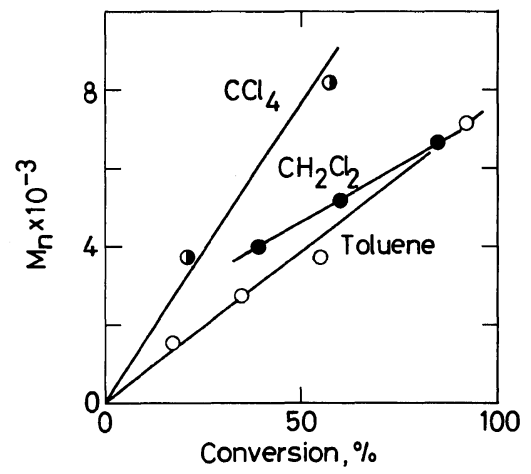

Figure 3. $M_{n}$-conversion plots for poly(CEVE) obtained with iodine at $-15^{\circ} \mathrm{C}:[\mathrm{M}]_{0}=0.50 \mathrm{M} ;\left[\mathrm{I}_{2}\right]_{0}=$ $10 \mathrm{mM}$. Solvents as indicated.

dine as an initiator and that their formation is favored in nonpolar solvents. Similar results have been obtained for the iodine-initiated polymerization of $p$-methoxystyrene $\mathrm{e}^{2,3}$ and IBVE. ${ }^{7}$

Monomer-Addition Experiments and Effect of Temperature. Addition of a new monomer feed to a completely polymerized solution (in toluene at $-15^{\circ} \mathrm{C}$ ) resulted in the resumption of polymerization and an increase in polymer molecular weight, which provided further evidence for the formation of long-lived polymers under these conditions. In a typical "monomer-addition" experiment, CEVE $(0.50 \mathrm{M})$ was completely polymerized with iodine $(20 \mathrm{mM})$ in toluene at $-15^{\circ} \mathrm{C}$, and to this reaction mixture was added the same amount of CEVE (neat). The second-stage polymerization immediately ensured at nearly the same rate as in the first, and the $M_{n}$ of the produced polymers further increased, again linearly with conversion.

The polymerization in toluene at a lower temperature $\left(-40^{\circ} \mathrm{C}\right)$ led to a linear $M_{n}-$ conversion plot similar to those for $-15^{\circ} \mathrm{C}$, whereas the $M_{n}$ values for $-40^{\circ} \mathrm{C}$ were slightly higher than those for $-15^{\circ} \mathrm{C}$, indicating the suppression of chain transfer and/or the retardation of initiation at this lower temperature.

As described above, long-lived propagating species were obtained in the CEVE polymerization with iodine in nonpolar solvents. However, the MWD of the polymers was rather broad $\left(M_{w} / M_{n}=1.4-1.6\right)$ with a long tailing. Thus the polymerization was an imperfect living polymerization, probably due to slow initiation.

\section{Polymerization with Hydrogen Iodide/Iodine}

Polymerization at $-15^{\circ} \mathrm{C}$. Recent studies in these laboratories have shown that mixtures of hydrogen iodide and iodine $\left(\mathrm{HI} / \mathrm{I}_{2}\right.$ initiator) induce living polymerizations of vinyl ethers to give monodisperse polymers. ${ }^{1,7,8}$ To achieve a perfectly living process for CEVE, this mono- 


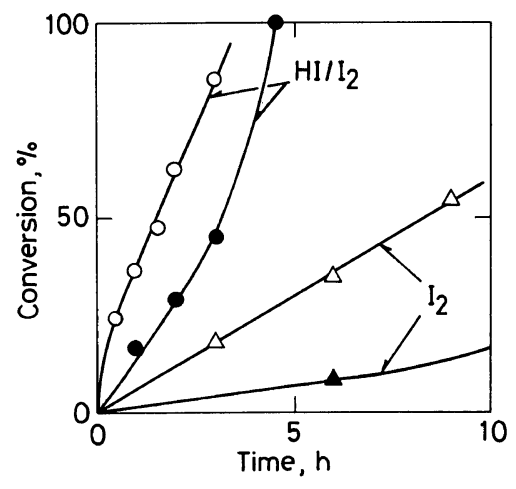

Figure 4. Conversion-time plots for the polymerization of CEVE with $\mathrm{HI} / \mathrm{I}_{2}$ or iodine at $-15^{\circ} \mathrm{C}$ : $[\mathrm{M}]_{0}=$ $0.50 \mathrm{M}$. Solvent and initiator: $(\mathrm{O})$ toluene, $[\mathrm{HI}]_{0}=$ $10 \mathrm{mM}, \quad\left[\mathrm{I}_{2}\right]_{0}=10 \mathrm{mM}$; (O) $\mathrm{CCl}_{4},[\mathrm{HI}]_{0}=12.5 \mathrm{mM}$, $\left[\mathrm{I}_{2}\right]_{0}=10 \mathrm{mM} ;(\triangle)$ toluene, $\left[\mathrm{I}_{2}\right]_{0}=10 \mathrm{mM}$ (from Figure 1); (A) $\mathrm{CCl}_{4},\left[\mathrm{I}_{2}\right]_{0}=10 \mathrm{mM}$ (from Figure 1).

mer was then polymerized with $\mathrm{HI} / \mathrm{I}_{2}$ initiator at $-15^{\circ} \mathrm{C}$ in toluene and $\mathrm{CCl}_{4}$ (Figure 4).

The reactions with $\mathrm{HI} / \mathrm{I}_{2}$ initiator were faster than with the same amount of iodine alone, as observed for the IBVE polymerization under similar conditions. ${ }^{7}$ This fact indicates that hydrogen iodide in conjunction with iodine accelerates the initiation and/or propagation in the polymerization of CEVE. The polymerizations in $\mathrm{CCl}_{4}$, either by $\mathrm{HI} / \mathrm{I}_{2}$ or iodine alone, showed an acceleration phase that was absent in those in toluene. Interestingly, no consumption of the monomer occurred within $24 \mathrm{~h}$ with hydrogen iodide alone in $\mathrm{CCl}_{4}$.

Figure 5 shows the MWD of the polymers obtained with $\mathrm{HI} / \mathrm{I}_{2}$ initiator in toluene and $\mathrm{CCl}_{4}$. The MWDs were considerably narrower $\left(M_{w} / M_{n}=1.2-1.3\right)$ than those obtained with iodine alone (Figure $2 \mathrm{~A} ; M_{w} / M_{n}=$ 1.4-1.6). These narrow distributions clearly shifted toward higher molecular weight with conversion. The narrowing of MWD indicated a faster initiation by $\mathrm{HI} / \mathrm{I}_{2}$ initiator than by iodine itself.

Figure 6 illustrates the $M_{n}$-conversion relationships for poly(CEVE) obtained with
(A) Toluene

(B) $\mathrm{CCl}_{4}$


Figure 5. MWD of poly(CEVE) obtained with $\mathrm{HI} / \mathrm{I}_{2}$ in toluene or $\mathrm{CCl}_{4}$ at $-15^{\circ} \mathrm{C}:[\mathrm{M}]_{0}=0.50 \mathrm{M}$. (A) $[\mathrm{HI}]_{0}=$ $10 \mathrm{mM}, \quad\left[\mathrm{I}_{2}\right]_{0}=10 \mathrm{mM} ;$ (B) $[\mathrm{HI}]_{0}=12.5 \mathrm{mM}, \quad\left[\mathrm{I}_{2}\right]_{0}=$ $10 \mathrm{mM}$.

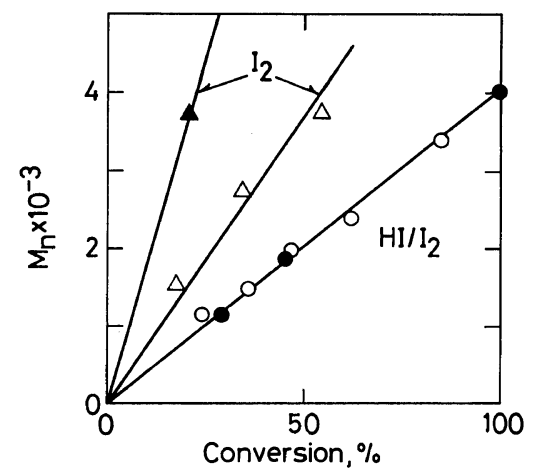

Figure 6. $M_{n}$-conversion plots for poly(CEVE) obtained with $\mathrm{HI} / \mathrm{I}_{2}$ or iodine in toluene or $\mathrm{CCl}_{4}$ at $-15^{\circ} \mathrm{C}$ : $[\mathrm{M}]_{0}=0.50 \mathrm{M}$. Solvent and initiator: (O) toluene, $[\mathrm{HI}]_{0}=10 \mathrm{mM}, \quad\left[\mathrm{I}_{2}\right]_{0}=10 \mathrm{mM} ;$ (O) $\mathrm{CCl}_{4}, \quad[\mathrm{HI}]_{0}=$ $12.5 \mathrm{mM}, \quad\left[\mathrm{I}_{2}\right]_{0}=10 \mathrm{mM} ;(\triangle)$ toluene, $\left[\mathrm{I}_{2}\right]_{0}=10 \mathrm{mM}$ (from Figure 3); (A) $\mathrm{CCl}_{4},\left[\mathrm{I}_{2}\right]_{0}=10 \mathrm{mM}$ (from Figure 3).

$\mathrm{HI} / \mathrm{I}_{2}$ initiator at $-15^{\circ} \mathrm{C}$. The $M_{n}$ 's proportional to conversion showed that in both toluene and $\mathrm{CCl}_{4}$ long-lived or living propagating species were obtained.

The $M_{n}$-conversion plots for the two solvents were nearly overlapping. This was in contrast to the corresponding plots obtained with iodine alone (Figure 3), which showed that at the same conversion the polymer molecular weight obtained in $\mathrm{CCl}_{4}$ was considerably greater than in toluene. Thus, the 
$\mathrm{HI} / \mathrm{I}_{2}$-initiated polymerization was less affected by the nature of solvents.

The $\mathrm{HI} / \mathrm{I}_{2}$-initiated polymerization of CEVE at $-15^{\circ} \mathrm{C}$ thus gave living-like polymers with a MWD narrower than that obtained with iodine alone. However, the MWD was close to but not monodisperse, showing a tailing particularly at higher conversion. Consequently, this reaction at $-15^{\circ} \mathrm{C}$ was still not a perfect living polymerization.

Polymerization at $-40^{\circ} \mathrm{C}$. CEVE was polymerized with $\mathrm{HI} / \mathrm{I}_{2}$ initiator at a lower temperature $\left(-40^{\circ} \mathrm{C}\right)$. Figure 7 shows the timeconversion profiles obtained at different

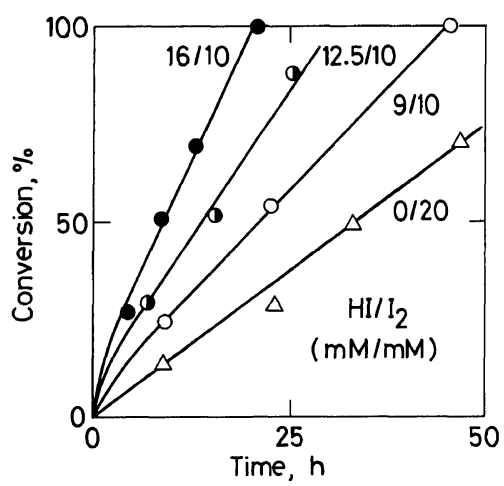

Figure 7. Conversion-time plots for the polymerization of $\mathrm{CEVE}$ with $\mathrm{HI} / \mathrm{I}_{2}$ or iodine in toluene at $-40^{\circ} \mathrm{C}$ : $[\mathrm{M}]_{0}=0.50 \mathrm{M}$. The initial concentrations of $\mathrm{HI}$ and iodine as indicated. charge ratios of hydrogen iodide to iodine $\left([\mathrm{HI}]_{0} /\left[\mathrm{I}_{2}\right]_{0}\right)$, together with the plot for iodine alone for comparison; in these experiments, the initial $\mathrm{HI}$ concentration $\left([\mathrm{HI}]_{0}\right)$ was varied while that of iodine $\left(\left[\mathrm{I}_{2}\right]_{0}\right)$ was kept constant $\left([\mathrm{HI}]_{0}=8.5-16 \mathrm{mM} ; \quad\left[\mathrm{I}_{2}\right]_{0}=10 \mathrm{mM}\right)$. The polymerization by $\mathrm{HI} / \mathrm{I}_{2}$ involved a sharp rise of conversion during the initial stage, followed by a slower phase giving a nearly linear conversion-time plot. The initial polymerization rate was greater with $\mathrm{HI} / \mathrm{I}_{2}$ initiator than with iodine alone, and increased at a higher $[\mathrm{HI}]_{0}$ or $[\mathrm{HI}]_{0} /\left[\mathrm{I}_{2}\right]_{0}$ ratio. The greater acceleration at higher $[\mathrm{HI}]_{0}$ suggests that the concentration of the propagating species is primarily determined by $[\mathrm{HI}]_{0}$ rather than by $\left[\mathrm{I}_{2}\right]_{0}$.

Figure 8 shows the MWD of the polymers obtained in toluene at $-40^{\circ} \mathrm{C}$. The MWD curves with $\mathrm{HI} / \mathrm{I}_{2}$ initiator shifted obviously toward higher molecular weight as the polymerization proceeded. They are much narrower than those obtained with iodine alone at $-40^{\circ} \mathrm{C}$ or with $\mathrm{HI} / \mathrm{I}_{2}$ at $-15^{\circ} \mathrm{C}$. With increasing $[\mathrm{HI}]_{0} /\left[\mathrm{I}_{2}\right]_{0}$ charge ratio, the tailing seen in the lower molecular weight region reduced and thereby the MWD progressively narrowed. Importantly, a nearly monodisperse MWD $\left(M_{w} / M_{n} \lesssim 1.1\right)$ was obtained at the highest $[\mathrm{HI}]_{0} /\left[\mathrm{I}_{2}\right]_{0}$. Similar monodisperse

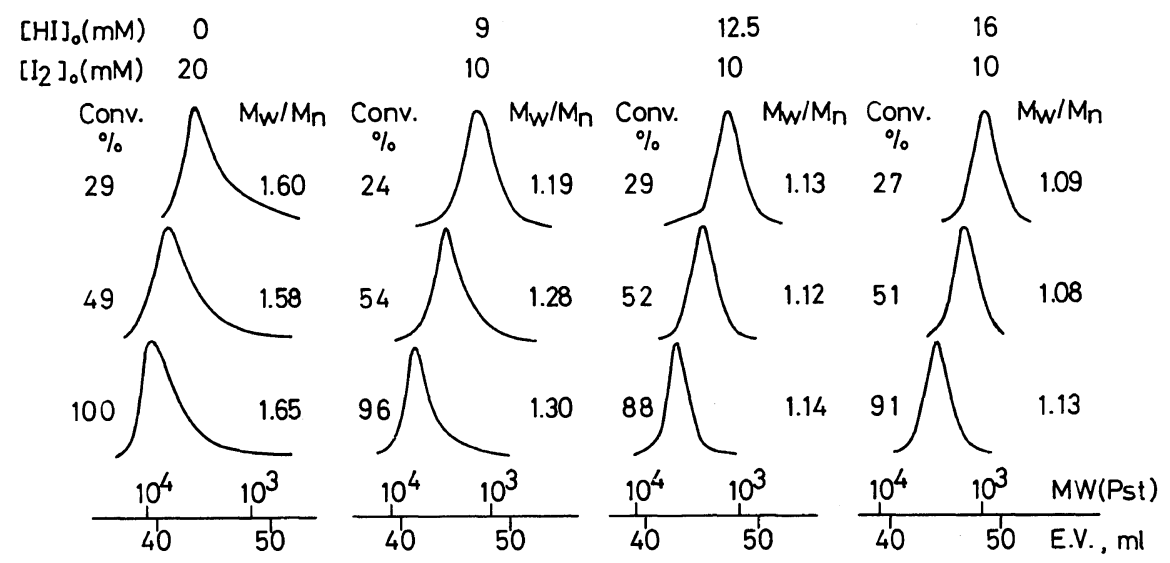

Figure 8. $\mathrm{MWD}$ of poly(CEVE) obtained with $\mathrm{HI} / \mathrm{I}_{2}$ or iodine in toluene at $-40^{\circ} \mathrm{C}:[\mathrm{M}]_{0}=0.50 \mathrm{M}$. Conversions, $M_{w} / M_{n}$ ratios, and the initial concentrations of $\mathrm{HI}$ and iodine as indicated. 


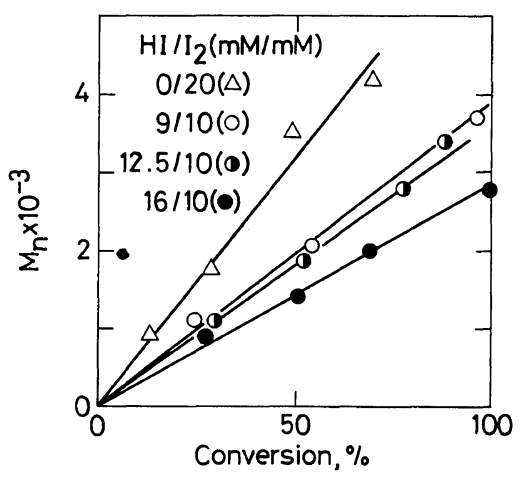

Figure 9. $M_{n}$-conversion plots for poly(CEVE) obtained with $\mathrm{HI} / \mathrm{I}_{2}$ or iodine in toluene at $-40^{\circ} \mathrm{C}$ : $[\mathrm{M}]_{0}=$ $0.50 \mathrm{M}$. The initial concentrations of $\mathrm{HI}$ and iodine as indicated.

MWDs have been observed for poly(alkyl vinyl ether)s obtained with an equimolar mixture of hydrogen iodide and iodine at $-5--15^{\circ} \mathrm{C} .^{7} \mathrm{CEVE}$, on the other hand, required an excess amount of the acid over iodine together with a lower temperature to yield such monodisperse polymers.

The $M_{n}$-conversion plots obtained at $-40^{\circ} \mathrm{C}$ were shown in Figure 9. The $M_{n}$ was directly proportional to conversion at all $[\mathrm{HI}]_{0} /\left[\mathrm{I}_{2}\right]_{0}$; at the same conversion, the higher the initial HI concentration, the lower the $M_{n}$ values. The results shown in Figures 8 and 9 demonstrated the formation of living polymers with a nearly monodisperse MWD in the CEVE polymerization by $\mathrm{HI} / \mathrm{I}_{2}$ initiator in toluene at $-40^{\circ} \mathrm{C}$.

It should be emphasized that a nearly perfect living polymerization was achieved for CEVE which would form a less stabilized propagating species. Comparison of this process with the corresponding living polymerization of $\mathrm{IBVE}^{7}$ indicated that CEVE needed to be polymerized at a lower temperature $\left(-40^{\circ} \mathrm{C}\right)$ than for IBVE $\left(-15^{\circ} \mathrm{C}\right)$ to yield nearly monodisperse living polymers. This may reflect the difference in stability between the propagating species derived from the two vinyl ethers.

\section{REFERENCES}

1. As a recent review, see $\mathrm{T}$. Higashimura and $\mathbf{M}$. Sawamoto, Adv. Polym. Sci., 62, 49 (1984).

2. T. Higashimura and O. Kishiro, Polym. J., 9, 87 (1977).

3. T. Higashimura, M. Mitsuhashi, and M. Sawamoto, Macromolecules, 12, 178 (1979).

4. T. Higashimura, H. Teranishi, and M. Sawamoto, Polym. J., 12, 393 (1980).

5. T. Higashimura, Y.-X. Deng, and M. Sawamoto, Polym. J., 15, 385 (1983).

6. T. Ohtori, Y. Hirokawa, and T. Higashimura, Polym. J., 11, 471 (1979).

7. M. Miyamoto, M. Sawamoto, and T. Higashimura, Macromolecules, 17, 265 (1984).

8. M. Miyamoto, M. Sawamoto, and T. Higashimura, Macromolecules, 17, Oct. issue (1984).

9. T. Iizawa, T. Nishikubo, M. Ichikawa, and $\mathbf{M}$. Okawara, Makromol. Chem., Rapid Commun., 4, 93 (1983). 